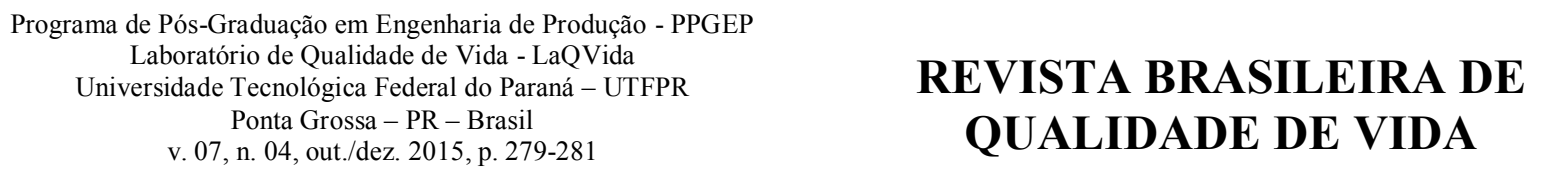

\section{REVISTA BRASILEIRA DE QUALIDADE DE VIDA}

\title{
Entrevista realizada com Wagner Wey Moreira
}

\author{
Luiz Alberto Pilatti \\ Universidade Tecnológica Federal do Paraná - UTFPR - Curitiba - Paraná - Brasil

Wagner Wey Moreira possui doutorado em Educação (Psicologia Educacional) e Livre Docência pela Universidade Estadual de Campinas (UNICAMP). Foi um dos criadores da Faculdade de Educação Física da UNICAMP. Publicou e organizou mais de uma dezena de livros, alguns já com elevado número de edições, entre eles Educação Física e Esportes: perspectivas para o século XXI e Qualidade de Vida: complexidade e educação. Já orientou 69 mestrados e 14 doutorados. Atualmente é professor da Universidade Federal do Triangulo Mineiro (UFTM).

Ressalta-se que foi mantida a entrevista na íntegra, visando preservar a originalidade do depoimento gentilmente oferecido pelo entrevistado, o qual agradecemos enormemente de antemão.

\section{O senhor poderia contar um pouco de sua trajetória acadêmica e da preocupação com a qualidade de vida?}

Minha vida acadêmica já se estende por mais quatro décadas. Tenho graduações em Educação Física e Pedagogia. Mestrado em Educação (área da Filosofia) pela Universidade Metodista de Piracicaba (UNIMEP); doutorado em Educação (Psicologia) pela Universidade Estadual de Campinas (UNICAMP) e Livro Docente pela mesma Instituição. Sou professor universitário há 36 anos, exercendo minha função docente e de pesquisador na UNICAMPCampinas, UNIMEP-Piracicaba, Universidade Federal do Pará (UFPA-Belém) e atualmente na Universidade Federal do Triângulo Mineiro (UFTM) em Uberaba. Exerci nessas Instituições de Ensino Superior os mais variados cargos, como Diretor Associado, Coordenador de Graduação e Pós Graduação, integrante das mais variadas comissões e colegiados, bem como exerço a liderança do Grupo de Estudos e Pesquisa Corporeidade e Pedagogia do Movimento (NUCORPO) há mais de 20 anos. Produzi e/ou coordenei mais de 20 livros, alguns com um grande número de reedições, bem como orientei 69 dissertações de mestrado e 15 teses de doutorado defendidas nas áreas da Educação e da Educação Física.

Quanto à preocupação com a qualidade de vida isto se deu, e ainda se dá, por entender que não é possível viver qualitativamente sem uma visão integral e integrada de corpo, bem como sem a ideia desse corpo em movimento, produzindo história e cultura e ao mesmo tempo sendo 
modificado por essa história e essa cultura. Como minha base epistemológica é a fenomenologia existencial, entendo que a busca e a manutenção da qualidade de vida se dá quando procuramos nos conhecer melhor, conhecer melhor os outros e conhecer melhor o mundo ou as coisas. Essa é a transcendência individual e coletiva.

\section{Gostaria que o senhor falasse um pouco do seu livro Qualidade de vida: complexidade e educação.}

A primeira edição deste livro se deu no ano de 2001, momento em que o assunto estava muito em moda e pensamos, eu e os articulistas do livro, imprimir uma obra que tentasse colocar alguns parâmetros axiológicos para a definição e/ou vivencia atitudinal de qualidade de vida. Estávamos preocupados com o senso comum apregoado por muitos e pelos meios de comunicação, de que qualidade de vida poderia se traduzir apenas em: consumir produtos mais sofisticados, como por exemplo, adquirir um belo apartamento com piscina e academia de ginástica (claro inacessível para a maioria da população); ter uma perspectiva de vida maior, mesmo não se alterando o modelo estressante de nossas relações; relacionar boa vida apenas com ausência de doenças e outros sentidos nesta direção.

Daí nasceu a estrutura do livro, em duas partes. A primeira, tentando apresentar o sentido complexo da qualidade de vida, abarcando os temas: cultura (John C. Dawsey em Coisa de Macunaíma: cultura e dialética da qualidade de vida); lazer (Nelson Carvalho Marcellino em Lazer e Qualidade de Vida); motricidade (Carol Kolyniak Filho em Qualidade de Vida e Motricidade); beleza estética (José Lima Junior em Qualidade de vida e beleza estética); e cuidado com o meio ambiente (Simone S. M. Guimarães em Qualidade de Vida X Qualidade do Ambiente). A segunda, enaltecendo a relação entre vida qualitativa e educação com textos sobre: educação dos sentidos (João Batista Freire em A Educação dos Sentidos e a Qualidade de Vida - A Escola de Dona Clotilde); inclusão de pessoas especiais (Eline T. R. Porto em Educação de Qualidade para Vidas Especiais - Um Caminho a Conquistar); preocupação com crianças e adolescentes (Ademir de Marco em Qualidade de Vida e Educação - A Infância e a Adolescência no Brasil); jovens e adultos (Trovão do Rosário em Qualidade de Vida - Juventude, Idade Adulta e Educação); e idosos (Regina Simões em Qualidade de Vida na (Qual)Idade de Vida). Todos estes testos foram introduzidos no livro por um capítulo escrito por mim que já trazia o foco da obra: Qualidade de Vida: Como Enfrentar esse Desafio? Ou seja, era uma provocação para novos olhares para o fenômeno em pauta.

\section{Qual a importância da Educação Física Escolar na qualidade de vida dos indivíduos?}

Creio que parte da resposta dessa pergunta já pode ser conferida com toda a segunda da parte do livro Qualidade de Vida: Complexidade e Educação. Mas, tentando ser bem específico sobre o tema e imaginando aulas de Educação Física nas escolas, sempre tenho dito que nós, dessa área, temos um conhecimento fabuloso para ser trabalhado junto aos alunos, principalmente os da Educação Básica, que facilmente pode ser entendido para incitar atitudes que levem a uma vida com qualidade.

Podemos explorar isto nos jogos e nos esportes, por exemplo, em que multiculturalismo, cooperação, ética, dependência, questões de gênero, padrões estéticos e outros tantos podem ser trabalhados e vivenciados pelos discentes de forma concreta, deixando esses assuntos de ser apenas algo hipotético e mesmo teórico como se apresentam muitas vezes nas escolas. É a Educação Física Escolar exercendo sua importância enquanto componente curricular no ensino formal. 


\section{Como enfrentar o desafio da qualidade de vida?}

Estabelecendo princípios norteadores do entendimento e da vivência da qualidade de vida. Alertando para os falsos conceitos sobre o tema, e isto só será possível a partir do momento em que se efetivar uma visão contextualizada e crítica do significado para a vida humana como um todo do que seja a tão alardeada qualidade de vida. Isso exige educar para mudança de valores, buscando estabelecer nos dizeres de Edgar Morin a ética do gênero humano, em que indivíduo/sociedade/espécie estabeleçam a concepção do gênero humano.

\section{O senhor gostaria de acrescentar algo que não foi abordado nesta entrevista?}

No sentido restrito à Qualidade de Vida não. Mas quero registrar meu agradecimento à oportunidade de emitir os pensamentos a respeito do assunto, ainda mais no momento em que, salvo melhor juízo, as confusões sobre o mesmo permanecem. Também agradeço a forma acadêmica e carinhosa de como foram construídas as perguntas, com o máximo de respeito à pluralidade de pensamento, requisito indispensável ao convívio de pesquisadores participantes de Instituições de Ensino Superior. Obrigado. 